\title{
PROBLEMATIC AND RISKY SEXUAL BEHAVIOUR UNDER THE INFLUENCE OF ALCOHOL AMONG UNIVERSITY STUDENTS
}

\author{
Benjamin Petruželka1, Miroslav Barták ${ }^{1,2}$, Vladimír Rogalewicz', Jozef Rosina ${ }^{3}$, Petr Popov¹, Beáta Gavurová4, \\ Martina Čierna $^{5}$, Ladislav Vaska ${ }^{6}$, Michaela Šavrnochová 6 , Martin Dlouhý7 \\ ${ }^{1}$ Department of Addictology, First Faculty of Medicine, Charles University and General University Hospital in Prague, Prague, Czech Republic \\ 2Department of Social Work, Faculty of Social and Economic Studies, Jan Evangelista Purkyně University, Ústí nad Labem, Czech Republic \\ ${ }^{3}$ Department of Health Care Disciplines and Population Protection, Faculty of Biomedical Engineering, Czech Technical University in Prague, \\ Kladno, Czech Republic \\ ${ }^{4}$ Centre for Applied Economic Research, Faculty of Management and Economics, Tomas Bata University in Zlín, Zlín, Czech Republic \\ ${ }^{5}$ Department of Social Work, Faculty of Education, Institute of Social Studies and Therapeutic Education, Comenius University in Bratislava, \\ Bratislava, Slovak Republic \\ ${ }^{6}$ Department of Social Work, Faculty of Education, Matej Bel University, Banská Bystrica, Slovak Republic \\ ${ }^{7}$ Department of Econometrics, Faculty of Informatics and Statistics, University of Economics, Prague, Czech Republic
}

\section{SUMMARY}

Objective: The objective of this research was to determine the prevalence of problematic and risky sexual behaviour after alcohol consumption and the correlation between this prevalence and sex, behavioural factors, problematic drinking, and alcohol consumption characteristics.

Methods: A survey of students was carried out at four faculties. Data were gathered via internet and self-administered paper-pencil questionnaires. The analysis employed Pearson's chi-squared test, gross odds ratios and logistic regression to calculate the adjusted odds ratios (OR) and their confidence interval $(\mathrm{Cl})$.

Results: Problematic drinking was detected by the CAGE test. Sixteen percent of students reached the CAGE score of 2, which indicates a potential threat of addiction, while $6 \%$ of students reached even higher problematic scores ( 3 or 4 ). Among those respondents who did drink alcohol, $23 \%$ had unprotected sex and $21 \%$ had sex which they later regretted. There were some differences between male and female respondents with men reporting more instances of risky behaviour. Among university students, problematic and risky sexual behaviour after alcohol use is associated with sex, the intensity of problematic drinking, first drunkenness, the place of alcohol use, and attitude to alcohol use.

Conclusions: Problematic drinking and risky sexual behaviour after alcohol consumption exist among students and deserve special attention and response in the form of suitable measures. Problematic and risky sexual behaviour after alcohol consumption among university students is associated with behavioural factors and characteristics of alcohol use that allow a targeted approach to preventive efforts.

Key words: alcohol, alcohol-related harm, sex, sexual behaviour, student

Address for correspondence: B. Petruželka, Department of Addictology, First Faculty of Medicine, Charles University and General University Hospital in Prague, Apolinářská 4, 12800 Prague 2, Czech Republic. E-mail benjamin.petruzelka@lf1.cuni.cz

https://doi.org/10.21101/cejph.a5195

\section{INTRODUCTION}

According to the WHO Global Status Report on Alcohol and Health, around 139 million disability-adjusted life years (DALYs), or $5.1 \%$ of the global burden of disease and injury, were attributable to alcohol consumption in 2012. Alcohol drinking is generally determined by factors like age, sex and socioeconomic status. While the university student population has a specific social status, it also shows a high prevalence of alcohol consumption as established in the systematic review conducted by Wicki et al. (1) and confirmed in the Czech and Slovak environment by numerous research projects (2-8). The following literature review focuses on the university student population as a subcategory of young adults with a typically higher alcohol consumption $(9,10)$.

The harmful use of alcohol is a component cause of more than 200 disease and injury conditions in individuals, most notably alcohol dependence, liver cirrhosis, cancers, and injuries (11). From the public health perspective, latest causal relationships suggested by research are those between harmful use of alcohol and infectious diseases such as tuberculosis or HIV/AIDS (11). Alcohol drinking is also associated with problematic and risky sexual behaviour (11-22). One of the causes of this situation is alcohol's role as a great facilitator in social situations (1) and sexual relations (15). Although the WHO (11) lists alcohol consumption and unprotected sex among behaviours responsible for a major share of the overall burden of diseases, authors of the WHO study 
(11) recognise that there is a lack of relevant literature on this topic. Adolescents and young adults $(12,23)$ make up the group that is most vulnerable to the negative consequences of alcohol use and risky sexual behaviour. The problem is compounded by the fact that alcohol use and the related risky sexual behaviour may jeopardise the evolution of future intimate relationships (21).

Kalina (12) describes three factors (psychological, behavioural and social) that influence risky sexual behaviour among adolescents and young adults, and believes that behavioural factors including alcohol drinking are crucial in risky sexual behaviour. Problematic drinking at a young age contributes to irresponsible sexual behaviour (22). A longitudinal study conducted by Guo et al. (20) detected a positive association between early problematic use of alcohol and the extent of problematic drinking later in life. Hingson et al. (17) describes the impact of the first drunkenness experience on risky sexual behaviour.

Selected studies have shown that risky sexual behaviour is present in Central and Eastern European countries. According to the OECD glossary (24), these countries include Albania, Bulgaria, Croatia, the Czech Republic, Hungary, Poland, Romania, the Slovak Republic, Slovenia, Estonia, Latvia, and Lithuania. For example, Czech and Slovak university students are more risk prone than their counterparts in Hungary and Lithuania, because they are less likely to use protection (condoms) in a sexual encounter with a new partner (13). Another study found that Czech and Slovenian respondents between the age 16 and 35 had unprotected (without a condom) sex more frequently than respondents from other countries included in the study (Austria, Germany, Greece, Italy, Portugal, Spain, and the United Kingdom) (15). Risky sexual behaviour among Slovak adolescents and young adults was studied by Kalina (12), who concluded that behavioural factors including alcohol consumption are strongly associated with risky sexual behaviour. However, his measure of alcohol consumption was merely the fact whether or not the students got drunk during the past month. This study (12) also confirmed the importance of the family and family structure as a protective factor against risky sexual behaviour. According to the WHO (11), alcohol creates an important sexual risk behaviour factor and needs to be seen also from the point of view of prevention activities. In the literature, the issues of prevention of HIV/AIDS (25), psychosocial distress (26), bullying (27), and/or sexual assault (28) are mostly mentioned.

The objective of our study was to determine the prevalence of problematic drinking (the assessment based on CAGE test scores) among university students and risky and problematic sexual behaviour under the influence of alcohol (assessed by the question about behaviour under the influence of alcohol) in this demographic group as well as associations between sexually risky behaviour under the influence of alcohol and behavioural factors and characteristics of alcohol use (extent of problematic drinking, early experience with alcohol, the place where students drink alcohol, and their attitude to alcohol). We decided to focus on the university student population because of the high prevalence of alcohol consumption and risky sexual behaviour in this population. Another objective of this paper is to compare existing findings in this area (22), derived primarily from U.S. research, with the situation in Central European countries. This is an important aim because research of this kind can highlight certain cross-cultural specifics, which may play an important role according to the WHO (11).

\section{MATERIALS AND METHODS}

\section{Participants and Procedures}

In the Czech Republic, data were collected at the Faculty of Social and Economic Studies of Jan Evangelista Purkyně University in Ústí nad Labem (UJEP). In Slovakia, data were collected at the Faculty of Education of Comenius University in Bratislava (UK), the Faculty of Education of Matej Bel University in Banská Bystrica (UMB), and the Faculty of Economics and other faculties of Technical University of Košice (TUKE). In the framework of the survey, the faculties were chosen due to their size, similarity of the study programmes, and availability for the survey. Finally, the collaborating universities were selected through personal contacts of researchers involved in the study - a similar procedure used in other studies (29). All participating universities are situated in structurally disadvantaged regions (according to national criteria), and the emergence of social problems is higher there in comparison with other regions in both countries (30).

Data were collected in the first half of 2015. This research was based on a selective questionnaire. The inclusion criterion was student's status at one of the included faculties. Recruitment strategies were the same in both countries. Questionnaires were distributed in printed version during the lectures, and a web survey was disseminated through students' communication channels (study group emails, student and university pages on the Facebook social network). The questionnaires were filled out anonymously, voluntarily, and without financial remuneration. The return rate was nearly $100 \%$ with the first (paper) mode. The second (electronic) mode complemented the data collected through the first approach. The participants were informed that by completing the survey they provided the informed consent to their participation in the study.

A total of 970 students were included in the final data set. Out of the final data set, 38\% of respondents studied at UJEP, $22 \%$ at UK, $17 \%$ at UMB, and $23 \%$ at TUKE, when $83 \%$ of respondents attended bachelor-level courses (28\% were students of the first year of bachelor courses, $27 \%$ of the second year, and $28 \%$ of the third year), and $17 \%$ of respondents studied master-level courses $(10 \%$ of respondents attended the fourth year of study, and $7 \%$ attended the fifth year of study). Women made up $80 \%$, and men $20 \%$ of the sample. This number is similar to other research $(13,29,31)$. Moreover, the number of women studying at these faculties exceeds the number of male students according to the Czech and Slovak ministerial statistics $(32,33)$. The biggest age group was that between 21 and 23 years, making up $67 \%$ of all respondents. Seventy-eight percent of respondents were in a relationship at the time. Most respondents were out-of-town students. Students attending university in their hometown made up $32 \%$ of all respondents, when $21 \%$ lodged in student dorms and $12 \%$ lived in privately hired rooms (Table 1 ).

\section{Measures}

\section{Risky and Problematic Sexual Behaviour}

As a part of the question cluster concerning behavioural problems linked with alcohol consumption (Have you ever got into trouble after drinking alcohol?), respondents were asked whether 


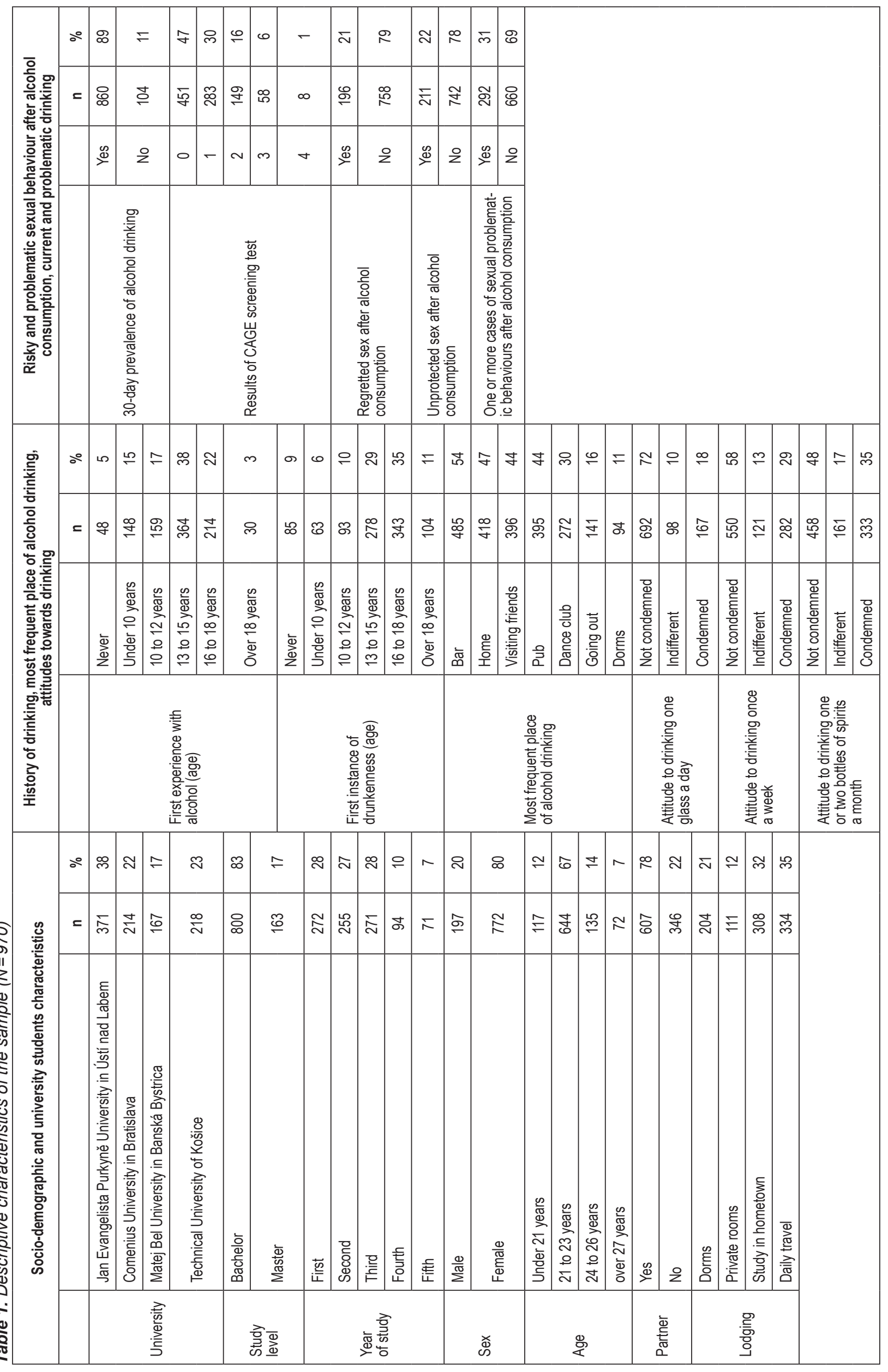


they had ever engaged in unprotected sex after drinking alcohol and whether they had ever regretted sex after drinking alcohol.

\section{Socio-demographic Characteristics}

Respondents were asked to provide the following sociodemographic information: age (indicating the appropriate age group: under 20, 21 to 23, 24 to 26, 27 and over), sex (male, female), type of housing (dorms, private rooms, daily commuting, study in their hometown), and whether or not they were in a relationship.

\section{CAGE Screening Test}

Our questionnaire included the CAGE screening test (34) designed to identify problematic drinking. The application of the test was described for example by Burešová and Vacek (2). The results yielded by the test were then used to determine the severity of drinking problem. The CAGE test consists of four questions. The number of "yes" responses represents the score index. Since the category of students with the score of 4 was very small (a total of eight respondents), it was merged with the score- 3 category for the purposes of further calculations.

\section{History of Drinking}

The respondents were also asked about the first time they had drunk alcohol and the first time they had got drunk (the "definition" of drunkenness was left up to each respondent). The multiple choice answers were as follows: never, before the age of 10, 10 to 12,13 to 15,16 to 18 , after the age of 18 .

\section{Most Frequent Place of Alcohol Drinking}

The respondents were then asked where they typically drank alcohol. Multiple answers could be given to this question out of the following choice: at home, while visiting friends, while going out, in a bar, in a dance club, in a pub.

\section{Attitudes Towards Drinking}

The last group of questions focused on the attitudes to alcohol. Respondents were asked whether they condemned listed forms of alcohol drinking (Do you personally condemn people who do the following?), and how strongly they felt about the following forms of drinking (I condemn this, I am indifferent, I do not condemn this): drinking one or two glasses of alcohol (beer, wine, spirits) a day; getting drunk once a week; drinking one or two bottles of spirits (strong distilled alcohol) a month.

\section{Statistical Analyses}

The data were processed using the Microsoft EXCEL 2013 and IBM SPSS 23 software. Similarly to the analyses performed by Cashell-Smith et al. (18) and Connor et al. (19), students who reported that they had never drank alcohol before were excluded from the analysis of association between problematic drinking and alcohol-related sexual experiences. Pearson's chi-squared test was used to test differences between groups (sexes). The initial evaluation of relations between variables was performed based on gross odds ratios. Multivariate logistic regression was used to calculate the adjusted odds ratios (OR) and their confidence interval (CI). Adjusted odds ratios were used because they are able to control for the influence of other variables.
In the first model, logistic regression analysis was conducted to control potential confounding of problematic drinking with socio-demographic characteristics (age, sex, relationship and accommodation). Other model sets were then used to detect the contribution of problematic drinking in the relationship between problematic/risky sexual behaviour and past drinking variables, attitudes toward alcohol and the place where students drink alcohol. The first model set focused on the relationship between the first experience with drunkenness, the severity of problematic drinking, and problematic/risky sexual behaviour. Models included in this set included socio-demographic characteristics, the age at which the respondent first got drunk, and a variable describing problematic/risky sexual behaviour. In addition to these, the second model set also included the extent of problematic drinking in order to control for this influence. The second model set focused on the relationship between attitudes toward alcohol and the extent of problematic drinking, and problematic and/or risky sexual behaviour. The third model set focused on the relationship between the place where respondents drink alcohol, the extent of problematic drinking and problematic/risky sexual behaviour.

\section{RESULTS}

During 30 days prior to filling-out the questionnaire, $89 \%$ of responding students drank alcohol, and the most frequent place of alcohol drinking was a bar (54\%). Problematic drinking was determined based on the CAGE test. A score of 2, which indicates potential risk of addiction, was reached by $16 \%$ of students, while $6 \%$ of students reached problematic values (a score of 3 or 4 ). The most frequent age of the first alcohol consumption is between 13 and 15 years ( $38 \%$ of respondents). Out of the respondents, $5 \%$ of students reported that they had no experience with drinking, while $9 \%$ of students declared that they had never been drunk, and among those with this experience, the first case of drunkenness happened most frequently between the age of 16 and 18 (35\% of respondents). The least condemned mode of alcohol drinking was one glass a day. The most condemned was drinking a bottle of spirits a month (Table 1).

Among respondents who have drunk alcohol ahead of that, $23 \%$ engaged in unprotected sex (Table 2). Differences between the sexes were tested (throughout the study) using Pearson's chisquared test, which highlighted systematic differences between the sexes $(p=0.001)$ with men having more unprotected sex than women. Regretted sex was reported by $21 \%$ of respondents. There were significant statistical differences between the sexes in this case $(p=0.006)$, when men had more regretted sexual experiences again. Out of all respondents, $32 \%$ had one or two such experiences with significant differences between the sexes $(p=0.001)$. Again, there were more men reporting such experiences. Furthermore, there are identifiable differences in the way men and women drink. On the sex level, we found statistically significant differences $(p=0.001)$ in the values scored in the CAGE test with men reaching higher CAGE scores. Differences between men and women are also apparent in terms of age when they first got drunk. The differences are statistically significant $(\mathrm{p}=0.001)$. Men had these experiences earlier than women (Table 2).

Using the gross odds ratio, we did not find a statistically significant relationship between variables such as having a partner, 
age and type of accommodation, and problematic and risky sexual behaviour after alcohol consumption. The only exception was a statistically significant relationship between private lodging and regretted sexual experiences $(p=0.034)$. Compared with individuals living in other types of accommodation, the gross odds ratio was 1.8. As shown in Table 3, the gross odds ratio of having a regretted sexual experience is higher for men (1.61) and increases with higher CAGE test scores. When all the variables are entered into a single model, the only statistically significant association to remain at a level of $5 \%$ is that between problematic drinking and regretted sex with the growing severity of problematic drinking increasing the odds of having regretted sex. In case of unprotected sex, there is a clear association between sex, the severity of problematic drinking, and this experiences, even if

Table 2. Gender differences in problematic sexual experiences, problematic drinking and first experince with drunkenness among students who tried alcohol during their life

\begin{tabular}{|c|c|c|c|c|c|c|c|c|}
\hline & & \multicolumn{2}{|c|}{ Total } & \multicolumn{2}{|c|}{ Women } & \multicolumn{2}{|c|}{ Men } & \multirow{2}{*}{$\begin{array}{c}\text { Comparison between } \\
\text { sexes } \\
\text { p-value }\end{array}$} \\
\hline & & $\mathrm{n}$ & $\%$ & $n$ & $\%$ & $\mathrm{n}$ & $\%$ & \\
\hline \multirow{2}{*}{ Regretted sex after alcohol consumption } & No & 698 & 79 & 569 & 80 & 128 & 71 & \multirow{2}{*}{0.006} \\
\hline & Yes & 190 & 21 & 138 & 20 & 52 & 29 & \\
\hline \multirow{2}{*}{ Unprotected sex after alcohol consumption } & No & 682 & 77 & 568 & 80 & 113 & 63 & \multirow{2}{*}{0.001} \\
\hline & Yes & 205 & 23 & 140 & 20 & 65 & 37 & \\
\hline \multirow{2}{*}{$\begin{array}{l}\text { One or more cases of problematic sexual } \\
\text { behaviour after alcohol consumption }\end{array}$} & No & 601 & 68 & 505 & 71 & 95 & 53 & \multirow{2}{*}{0.001} \\
\hline & Yes & 285 & 32 & 202 & 29 & 83 & 47 & \\
\hline \multirow{4}{*}{ Results of CAGE screening test } & 0 & 400 & 45 & 335 & 48 & 65 & 36 & \multirow{4}{*}{0.001} \\
\hline & 1 & 277 & 32 & 224 & 32 & 52 & 29 & \\
\hline & 2 & 144 & 16 & 114 & 16 & 30 & 17 & \\
\hline & 3 or 4 & 63 & 7 & 30 & 4 & 33 & 18 & \\
\hline \multirow{5}{*}{ Age of first drunkenness } & Under 10 years & 62 & 7 & 34 & 5 & 28 & 17 & \multirow{5}{*}{0.001} \\
\hline & 10 to 12 years & 89 & 11 & 57 & 9 & 32 & 19 & \\
\hline & 13 to 15 years & 268 & 32 & 222 & 33 & 46 & 27 & \\
\hline & 16 to 18 years & 325 & 38 & 272 & 40 & 53 & 32 & \\
\hline & Over 18 years & 97 & 12 & 88 & 13 & 8 & 5 & \\
\hline
\end{tabular}

Table 3. Association of current drinking and socio-demographics variables with regretted sexual experiences or unsafe sex due to drinking

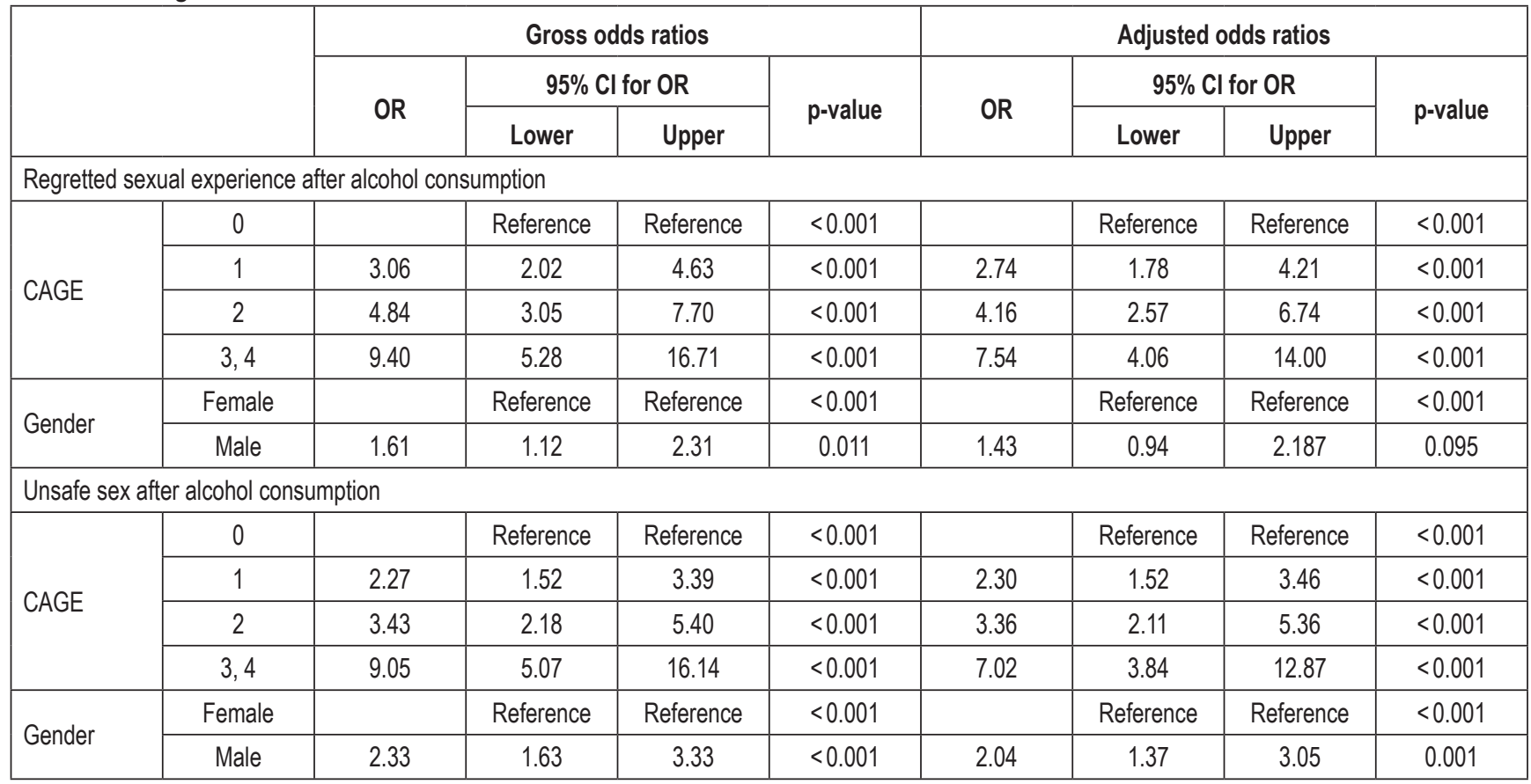


all the variables discussed above are entered into the model. The combination of increasing severity of problematic drinking and the male sex increases the odds of having unprotected sex (Table 3).

Table 4 shows models for the relationship between the age of the first drunk experience and problematic and/or risky sexual experiences. A significant relationship between the age of the first alcohol consumption and problematic sexual experiences was not detected. The first model yielded a statistically significant relationship between the age of the first drunk experiences and unsafe/regretted sex. Adjusted odds ratios of problematic and risky sexual behaviour for respondents, who had their first drunk experience after the age of 18 , were approaching zero (Table 4). The relationship between the age of the first drunk experience and regretted sex remains statistically significant even after entering the variable reflecting the severity of problematic drinking, while the relationship between unsafe sex and the age of the first drunk experience loses its statistical significance. There is a strong relationship between regretted sexual experiences and first drunkenness. The odds of having a regretted sexual experience approaches zero for respondents, who got drunk for the first time after the age of 18. Thus, it is apparent that sexual experiences that students later regret are not associated with the age, at which the student first drank alcohol but there is a strong association with the age at which the student first got drunk (Table 4).

Significant relationships were detected between the frequent place of alcohol drinking and problematic and risky sexual experiences (Table 5). Drinking in a bar or a dance club increases the odds of having regretted sex after drinking alcohol. After introducing the CAGE variable into the model, the relationship between drinking in a bar and regretted sex after alcohol consumption remains statistically significant. Drinking while going out or at a dance club increases the odds of having unprotected sex after alcohol consumption. What remains after introducing the CAGE variable is the statistically significant relationship between drinking at a dance club and unsafe sex (Table 5). No significant relationships were detected between respondents' attitude to alcohol and regretted sex. There was a significant relationship between unsafe sex and the attitude to alcohol, namely in terms of condemnation of getting drunk once a week. For those condemning weekly drunkenness, the odds of having unsafe sex remain unchanged (as compared with those who do not condemn this behaviour) even when the problematic drinking variable is introduced (Table 6).

\section{DISCUSSION}

In our research, we focused on the relationship between alcohol drinking and some of its consequences among university students, looking specifically at socio-demographic variables, variables reflecting the characteristic traits of alcohol use, and problematic and/or risky sexual behaviour. A questionnaire survey among university students confirmed that some students drink at a problematic level with $6 \%$ of respondents scoring 3 or 4 in the CAGE test. We also established a relatively high level of problematic and risky sexual behaviour after alcohol consumption among university students. Among the students who drank alcohol, 23\% had unsafe sex and $21 \%$ had sex that they later regretted. Unsafe sex or regretted sex, or both of these experiences, were reported by $32 \%$ of students. A significant number of students encountered alcohol at an early age, with $50 \%$ of them getting drunk for the first time before the age of 15 .

The effect of problematic drinking on problematic sexual behaviour has been the subject of numerous studies (12, 14-20) that have all established a positive association between these two types of behaviour. However, Cooper (35) notes that studies show varying influence of alcohol consumption on the use of condoms. Záškodná (36) states that among university students unwanted sex is linked to alcohol in $35 \%$ of cases. In line with the papers by Cashell-Smith et al. (18) and Connor et al. (19),

Table 4. Association of first drunkenness with unsafe sex or regretted sexual experiences due to drinking (Model 1), and association of first drunkeness with unsafe sex or regretted sexual experiences due to drinking adjusted for contribution of problematic drinking level (Model 2).

\begin{tabular}{|c|c|c|c|c|c|c|c|c|c|}
\hline & & \multicolumn{4}{|c|}{ Model 1} & \multicolumn{4}{|c|}{ Model 2} \\
\hline & & \multirow{2}{*}{ OR } & \multicolumn{2}{|c|}{$95 \% \mathrm{Cl}$ for OR } & \multirow{2}{*}{ p-value } & \multirow{2}{*}{ OR } & \multicolumn{2}{|c|}{$95 \% \mathrm{Cl}$ for OR } & \multirow{2}{*}{ p-value } \\
\hline & & & Lower & Upper & & & Lower & Upper & \\
\hline \multicolumn{10}{|c|}{ Regretted sexual experience after alcohol consumption } \\
\hline \multirow{5}{*}{$\begin{array}{l}\text { Age of first } \\
\text { drunkenness }\end{array}$} & Under 10 years & & & & $<0.001$ & & & & 0.001 \\
\hline & 10 to 12 years & 0.53 & 0.25 & 1.15 & 0.107 & 0.59 & 0.27 & 1.30 & 0.193 \\
\hline & 13 to 15 years & 0.89 & 0.46 & 1.71 & 0.727 & 1.12 & 0.56 & 2.21 & 0.750 \\
\hline & 16 to 18 years & 0.50 & 0.26 & 0.97 & 0.039 & 0.68 & 0.34 & 1.35 & 0.267 \\
\hline & Over 18 years & 0.01 & 0.03 & 0.29 & $<0.001$ & 0.15 & 0.04 & 0.50 & 0.002 \\
\hline \multicolumn{10}{|c|}{ Unsafe sex after alcohol consumption } \\
\hline \multirow{5}{*}{$\begin{array}{l}\text { Age of first } \\
\text { drunkenness }\end{array}$} & Under 10 years & & & & $<0.001$ & & & & $<0.001$ \\
\hline & 10 to 12 years & 1.72 & 0.81 & 3.63 & 0.157 & 2.07 & 0.95 & 4.54 & 0.068 \\
\hline & 13 to 15 years & 1.49 & 0.75 & 2.97 & 0.256 & 1.93 & 0.94 & 4.00 & 0.075 \\
\hline & 16 to 18 years & 0.74 & 0.37 & 1.49 & 0.399 & 1.02 & 0.49 & 2.13 & 0.958 \\
\hline & Over 18 years & 0.22 & 0.07 & 0.63 & 0.005 & 0.36 & 0.12 & 1.09 & 0.071 \\
\hline
\end{tabular}

Logistic regression models included age, gender, living conditions, having a partner. 
Table 5. Association favorite place of drinking with unsafe sex and regretted sexual experiences due to drinking (Model 1), and contribution of problematic drinking level (Model 2).

\begin{tabular}{|c|c|c|c|c|c|c|c|c|c|}
\hline & & \multicolumn{4}{|c|}{ Model 1} & \multicolumn{4}{|c|}{ Model 2} \\
\hline & & \multirow{2}{*}{ OR } & \multicolumn{2}{|c|}{$95 \% \mathrm{Cl}$ for OR } & \multirow{2}{*}{ p-value } & \multirow{2}{*}{ OR } & \multicolumn{2}{|c|}{$95 \% \mathrm{Cl}$ for OR } & \multirow{2}{*}{ p-value } \\
\hline & & & Lower & Upper & & & Lower & Upper & \\
\hline \multicolumn{10}{|c|}{ Regretted sexual experience after alcohol consumption } \\
\hline \multirow{7}{*}{$\begin{array}{l}\text { Frequent } \\
\text { place of } \\
\text { drinking }\end{array}$} & Home & 1.23 & 0.87 & 1.75 & 0.240 & 1.29 & 0.89 & 1.86 & 0.177 \\
\hline & Visiting friends & 1.07 & 0.76 & 1.50 & 0.701 & 1.04 & 0.73 & 1.48 & 0.817 \\
\hline & Going out & 1.40 & 0.90 & 2.17 & 0.137 & 1.16 & 0.73 & 1.84 & 0.529 \\
\hline & Bar & 1.65 & 1.16 & 2.36 & 0.006 & 1.48 & 1.02 & 2.15 & 0.041 \\
\hline & Dance club & 1.49 & 1.03 & 2.16 & 0.034 & 1.35 & 0.92 & 1.99 & 0.160 \\
\hline & Pub & 1.33 & 0.94 & 1.89 & 0.104 & 1.33 & 0.92 & 1.92 & 0.127 \\
\hline & Dorms & 1.31 & 0.70 & 2.44 & 0.397 & 1.27 & 0.66 & 2.44 & 0.470 \\
\hline \multicolumn{10}{|c|}{ Unprotected sex after alcohol consumption } \\
\hline \multirow{7}{*}{$\begin{array}{l}\text { Most } \\
\text { frequent } \\
\text { place of } \\
\text { drinking }\end{array}$} & Home & 1.21 & 0.86 & 1.72 & 0.277 & 1.26 & 0.88 & 1.81 & 0.213 \\
\hline & Visiting friends & 1.19 & 0.86 & 1.67 & 0.299 & 1.19 & 0.84 & 1.68 & 0.331 \\
\hline & Going out & 1.72 & 1.12 & 2.62 & 0.012 & 1.49 & 0.96 & 2.32 & 0.074 \\
\hline & Bar & 1.56 & 1.10 & 2.21 & 0.013 & 1.40 & 0.97 & 2.01 & 0.073 \\
\hline & Dance club & 1.95 & 1.36 & 2.80 & $<0.001$ & 1.82 & 1.25 & 2.65 & 0.002 \\
\hline & Pub & 1.22 & 0.86 & 1.72 & 0.259 & 1.19 & 0.83 & 1.70 & 0.352 \\
\hline & Dorms & 1.72 & 0.94 & 3.13 & 0.079 & 1.71 & 0.91 & 3.19 & 0.093 \\
\hline
\end{tabular}

Logistic regression models included age, gender, living conditions, having a partner.

Table 6. Association of attitudes towards drunkenness with unsafe sex (Model 1), and contribution of problematic drinking level (Model 2).

\begin{tabular}{|c|c|c|c|c|c|c|c|c|c|}
\hline & & \multicolumn{4}{|c|}{ Model 1} & \multicolumn{4}{|c|}{ Model 2} \\
\hline & & \multirow{2}{*}{ OR } & \multicolumn{2}{|c|}{$95 \% \mathrm{Cl}$ for OR } & \multirow{2}{*}{$\mathrm{p}$-value } & \multirow{2}{*}{ OR } & \multicolumn{2}{|c|}{$95 \% \mathrm{Cl}$ for OR } & \multirow{2}{*}{ p-value } \\
\hline & & & Lower & Upper & & & Lower & Upper & \\
\hline \multicolumn{10}{|c|}{ Unsafe sex after alcohol consumption } \\
\hline \multirow{3}{*}{$\begin{array}{l}\text { Drinking } \\
\text { once a week }\end{array}$} & Not condemned & & & & $<0.001$ & & & & 0.001 \\
\hline & Indifferent & 0.66 & 0.37 & 1.17 & 0.155 & 0.75 & 0.41 & 1.35 & 0.331 \\
\hline & Condemned & 0.34 & 0.20 & 0.57 & 0.001 & 0.34 & 0.20 & 0.59 & 0.001 \\
\hline
\end{tabular}

Logistic regression models included age, gender, living conditions, having a partner.

our study found that the odds ratio of engaging in a risky sexual behaviour increases among university students with an increasing severity of problematic drinking, both in terms of regretted sex and in terms of unsafe sex.

In the university student population, there are also differences between the sexes in terms of alcohol consumption $(1,37)$ as well as in terms of problematic and risky sexual experiences after drinking $(18,19)$. As for variables that reflect both problematic and risky sexual behaviour and the extent of problematic drinking and the age of first experience with being drunk, there are statistically significant differences between the two sexes. Men more likely act in a more problematic and risky manner, when it comes to sex and drinking. Men also get their first experience with alcohol earlier than women. If we introduce sex as a variable in the model along with other socio-demographic factors and the extent of problematic drinking, the relationship between sex (male/female) and regretted sex loses its statistical significance. However, the statistically significant relationship between male/ female and unsafe sex remains with men being more likely engaged in regretted sex. It raises a question how to explain the different results in terms of the amount of risky sexual behaviour that we see for men and women. One interpretation of the results may be that our respondents had sexual partners who were not themselves included in the studied sample population. Since we did not study the characteristics of the sexual partners of our respondents, this hypothesis may be an inspiration for future research. Another possible explanation of the differences may be different perception of sexual experience by one of the partners. A review by Wicki et al. (1) suggests a higher prevalence of problematic drinking among university students who live alone or in dorms. Cashell-Smith et al. (18) reported that shared living or accommodation in dorms (compared with other types of lodging) is linked to greater odds of risky sexual behaviour after alcohol consumption. Using the gross odds ratio, we failed to establish a statistically significant relationship between the accommodation variable and problematic and risky sexual behaviour after alcohol consumption. The only exception was a statistically relevant relationship between private lodging and regretted sex experiences 
$(p=0.034)$. Compared with individuals living in other types of lodging, the gross odds ratio was 1.8. However, when controlled for other factors, this relationship disappeared.

The influence of early encounters with alcohol on risky sexual behaviour has been confirmed by several studies $(17,19,38,39)$. In our study we did not see an effect of an early first alcoholic drink, as was the case among university students in New Zealand (19), but we did find an effect of the first case of drunkenness. Respondents who got drunk for the first time later in life had a lower chance of experiencing regretted sex. Similar findings apply to unsafe sex. However, after controlling for the extent of problematic drinking, this association loses its statistical relevance.

An important finding is that problematic and risky sexual behaviour after alcohol consumption is linked to the place where the respondents usually drink. The association of the bar as the frequent place of drinking and regretted sex may be interpreted in the light of the fact that bars are often the place where students meet new people and look for sexual partners. Unsafe sex is also linked to drinking at dance clubs, which, like bars, may be seen as a high-risk environment. These findings are in line with the WHO opinion that alcohol-serving venues are also places of sexual encounters (11).

Cashell-Smith et al. (18) found an association between specific attitudes to drinking ("Drinking makes sex better", "Drinking gives me confidence to approach people I am attracted to", "Drinking reduces my inhibitions") and risky sexual behaviour. Kalina (12) links unsafe sex, especially after alcohol consumption, with lowered self-control and positive socially-oriented values. Our study also focused on attitudes and values. However, we studied attitudes and values in relation to drinking because our aim was to establish whether one's attitude to alcohol, rather than simply the immediate level of problematic drinking, is associated with problematic and risky sexual behaviour. Our study yielded interesting results, because unsafe sex after alcohol consumption is in a statistically significant relationship to one's attitude to alcohol, namely to condemnation of drinking once a week, which decreases the probability of unsafe sex. This association does not disappear even when the problematic drinking variable is introduced to the model, which may lead us to conclude that unsafe sex, rather than regretted sex, is linked not only to the extent of problematic drinking, but also to personal attitudes to alcohol. The prevention activities are highly recommended based on the results of the survey. Such activities may address individual behaviour patterns, general behavioural patterns, as well as the social and cultural behavioural patterns (11), particularly the prevention activities may address drinking alcohol before sex and well casual sexual relationships. This may incorporate both individual behaviour patterns as well as other above-mentioned patterns specifically for university students.

\section{CONCLUSIONS}

Our findings confirm that problematic and risky sexual behaviour after alcohol consumption is associated with behavioural factors among university students. One of the factors that support problematic and risky sexual behaviour is the age at which the respondent first got drunk. Like Hingson et al. (17), we can recommend delaying the moment when people get drunk for the first time. Thus, the desirable way how to decrease risky sexual behaviour among students would be a stricter enforcement of legal drinking age to postpone the onset of regular drinking and to lower alcohol consumption in the general population using the measures recommended by the WHO (40). We can also recommend that more attention was paid to the male university student population, where we see more risky behaviour, as well as to university students frequenting bars and dance clubs. It is advisable to conduct larger studies to understand this population better, which would enable preventionists to tailor specific prevention activities for delivery in bars and dance clubs, for example an information or condom distribution campaign. For example, Magalhaes et al. (41) discuss the fact that students frequently draw information on the sexual behaviour from their friends, which may be problematic. Considering the condom distribution campaign, Schuster et al. (42) noted that high school condom availability programme appears to have led to improved condom use among males. In the future, research in this area in the Central European region could go into greater details on attitudes to alcohol and ways to address them. The limits of our research stem from the fact that it was restricted to the specific population of young adults, namely university students, and from the use of a cross-section selective inquiry as well as the sampling procedure, which poses a concern. However, our procedure was almost equivalent to other studies (43). The authors did not concentrate on a representative country study showing international differences, but they highlighted the relationship between alcohol use and sexual behaviour in Central Europe generally. Future studies could build on our results with an event-specific research (35) devoted to recording specific events and relevant circumstances. It could help us better understand the causal mechanisms involved in the occurrence of risky and problematic sexual behaviour. The future research could also focus not only on the experience of respondents, but also on the experience of their sexual partners and their mutual experience. It could also be interesting to include other young people, not only university students but also other individuals who have sexual relations with university students.

\section{Conflict of Interests}

None declared

\section{Acknowledgement}

Authors affiliated to the First Faculty of Medicine, Charles University and General University Hospital in Prague were supported by the Progress No. Q06/LF1 grant. For author Miroslav Barták this article was supported by J. E. Purkyně University in Ústí nad Labem internal grant No. UJEPIGS-2018-45-001-1. For authors affiliated to Matej Bel University the article was made possible by the program VEGA No. 1/0692/18.

\section{REFERENCES}

1. Wicki M, Kuntsche E, Gmel G. Drinking at European universities? A review of students' alcohol use. Addict Behav. 2010;35(11):913-24.

2. Burešová Z, Vacek J. Alcohol among students at the 1st Faculty of Medicine of Charles University: prevalence of use and associated risk behaviours. Addictology. 2012;12(2):90-100. (In Czech.)

3. Csémy L, Hrachovinová T, Krch DF. Alcohol consumption and illicit substance use in Prague university student. Addictology. 2004;4(2):12435. (In Czech.) 
4. Kolibáš E, Novotný V, Turek M. Experiences of students of selected colleges with psychoactive substances. Alkohol Drog Zavisl. 2008;43(4):221-32. (In Slovak.)

5. Nociar A. Drug survey on university students in Slovakia. Final report. Bratislava: St. Elisabeth University of Health Care and Social Work; 2014. (In Slovak.)

6. Trojáčková A. Addictive substances - Attitudes and experiences of university students. Hradec Králové: Charles University, Faculty Of Pharmacy in Hradec Králové; 2006. (In Czech.)

7. Vacek J, Holcnerová P. Substance use among university students in the Czech Republic. Alkohol Drog Zavisl. 2010;45(3):129-48. (In Czech.)

8. Petruželka B, Barták M, Rogalewicz V, Popov P, Gavurová B, Dlouhý M, et al. Alcohol use and related problems among students of social work at selected universities in the Czech Republic and Slovakia - a pilot study of the risky periods. Addictology. 2017;17(2):108-17. (In Czech.)

9. Dawson DA, Grant BF, Stinson FS, Chou PS. Another look at heavy episodic drinking and alcohol use disorders among college and noncollege youth. J Stud Alcohol. 2004;65(4):477-88.

10. Kypri K, Cronin M, Saunders JB, Wright CS. Do university students drink more hazardously than their Non $\square$ student peers? Addiction. 2005;100(5):713-4

11. World Health Organization. Alcohol use and sexual risk behaviour: a cross-cultural study in eight countries. Geneva: WHO; 2005.

12. Kalina O. Sexual risky behaviour among Slovak adolescents and young adults: social and psychological factors [dissertation]. Košice: Equilibria; 2012.

13. Janovská A, Orosová O, Jurystová L. Risk behaviour of university students in the context selected socio-demographic characteristics comparison of four countries as part of the SliCE International Study. Addictology. 2014;14(2):134-44. (In Slovak.)

14. Dlouhý M, Barták M, Pěnčíková L. Alcohol among Students of Social Work Study Programme. Eur J Public Health. 2016;26 Suppl 1:ckw174.159. doi: 10.1093/eurpub/ckw174.159.

15. Bellis MA, Hughes K, Calafat A, Juan M, Ramon A, Rodriguez JA, et al. Sexual uses of alcohol and drugs and the associated health risks: a cross sectional study of young people in nine European cities. BMC Public Health. 2008;8(1):155. doi: 10.1186/1471-2458-8-155.

16. Murgraff V, Parrott A, Bennett P. Risky single-occasion drinking amongst young people - definition, correlates, policy, and intervention: a broad overview of research findings. Alcohol Alcoholism. 1999;34(1):3-14

17. Hingson R, Heeren T, Winter MR, Wechsler H. Early age of first drunkenness as a factor in college students' unplanned and unprotected sex attributable to drinking. Pediatrics. 2003;111(1):34-41.

18. Cashell-Smith ML, Connor JL, Kypri K. Harmful effects of alcohol on sexual behaviour in a New Zealand university community. Drug Alcohol Rev. 2007;26(6):645-51.

19. Connor J, Gray A, Kypri K. Drinking history, current drinking and problematic sexual experiences among university students. Aust N Z J Public Health. 2010;34(5):487-94.

20. Guo J, Chung IJ, Hill KG, Hawkins JD, Catalano RF, Abbott RD. Developmental relationships between adolescent substance use and risky sexual behavior in young adulthood. J Adolescent Health. 2002;31(4):354-62.

21. Boyd CJ, McCabe SE, Morales M. College students' alcohol use: a critical review. Ann Rev Nurs Res. 2005;23(1):179-211.

22. Newbury-Birch D, Walker J, Avery L, Beyer F, Brown N, Jackson K, et al. Impact of alcohol consumption on young people: a systematic review of published reviews. Newcastle: Newcastle University; 2009.

23. Gavurova, B. Analysis of regional disparities of development in the number of drug addicted and its importance for health policy of Slovakia. In: 3rd International Multidisciplinary Scientific Conference on Social Sciences and Arts (SGEM 2016); 2016 Aug 24-31; Albena, Bulgaria. Sofia: International Multidisciplinary Scientific GeoConferences (SGEM); 2016. p. 129-40.

24. Organisation for Economic Co-operation and Development. Central and Eastearn European Countries (CEECS) [Internet]. OECD; 2001 [cited 2017 Aug 7]. Available from: https://stats.oecd.org/glossary/detail. asp? ID $=303$.
25. Boyer CB, Greenberg L, Chutuape K, Walker B, Monte D, Kirk J, et al. Exchange of sex for drugs or money in adolescents and young adults: an examination of sociodemographic factors, HIV-related risk, and community context. J Community Health. 2017;42(1):90-100.

26. Chanakira E, Goyder EC, Freeman JV, O'Cathain A, Kinghorn G, Jakubovic M. Social and psychosocial factors associated with high-risk sexual behaviour among university students in the United Kingdom: a web-survey. Int J STD AIDS. 2015;26(6):369-78.

27. Hertz M, Jones SE, Barrios L, David-Ferdon C, Holt M. Association between bullying victimization and health risk behaviors among high school students in the United States. J Sch Health. 2015;85(12):833-42.

28. Hoxmeier JC, Flay BR, Acock AC. Control, norms, and attitudes: differences between students who do and do not intervene as bystanders to sexual assault. J Interpers Violence. 2018;33(15):2379-401.

29. Helmer SM, Sebena R, McAlaney J, Petkeviciene J, Salonna F, Lukacs A, et al. Perception of high alcohol use of peers is associated with high personal alcohol use in first-year university students in three central and Eastern European Countries. Subst Use Misuse. 2016;51(9):1224-31.

30. Kuchař P, Vaska L, editors. Regional aspects of unemployment in the Czech Republic and Slovakia. Bratislava: IRIS; 2014. (In Slovak.)

31. Kulanová M, Orosová O. Alcohol consumption, perceived stress and plans to move abroad among university students. Eur J Public Health. 2016;26 Suppl 1:ckw174.027. doi: 10.1093/eurpub/ckw174.027.

32. Ministry of Education, Youth and Sports. Data on university students, first enroled and graduated [Internet]. Prague: MEYS; c2013-2018 [cited 2018 Oct 12]. Available from: http://www.msmt.cz/vzdelavani/skolstvi-v-cr/ statistika-skolstvi/data-o-studentech-poprve-zapsanych-a-absolventechvysokych. (In Czech.)

33. Slovak Centre of Scientific and Technical Information. Statistics yearbook - universities [Internet]. Bratislava: SCSTI; 2018 [cited 2018 Oct 12]. Available from: http://www.cvtisr.sk/cvti-sr-vedecka-kniznica/ informacie-o-skolstve/statistiky/statisticka-rocenka-publikacia/statisticka-rocenka-vysoke-skoly.html?page_id=9596. (In Slovak.)

34. Erwing JA. Detecting alcoholism: The CAGE questionnaire. JAMA. 1984;252(14):1905-7.

35. Cooper ML. Alcohol use and risky sexual behavior among college students and youth: evaluating the evidence. J Stud Alcohol Suppl. 2002;(14):101-17.

36. Záškodná H. Experiences with drugs among students of University of South Bohemia. Zavis My. 2004;4(2):22-5. (In Czech.)

37. Adámková TP, Vondráčková $\mathrm{P}$, Vacek J. Alcohol abuse among university students. Addictology. 2009;9(2):96-103. (In Czech.)

38. Santelli JS, Robin L, Brener ND, Lowry R. Timing of alcohol and other drug use and sexual risk behaviors among unmarried adolescents and young adults. Family Plann Perspect. 2001;33(5):200-5.

39. Stueve A, O'donnell LN. Early alcohol initiation and subsequent sexual and alcohol risk behaviors among urban youths. Am J Public Health. 2005;95(5):887-93.

40. World Health Organization. Global strategy to reduce the harmful use of alcohol. Geneva: WHO; 2010.

41. Magalhaes Z, Castro R, Pereira F. Risk factors sexual behaviour and C. trachomatis infection among Health Sciences University students in Lisbon. J Infect Dis Epidemiol. 2016;2(1). doi: 10.23937/2474-3658/1510005.

42. Schuster MA, Bell RM, Berry SH, Kanouse DE. Impact of a high school condom availability program on sexual attitudes and behaviors. Fam Plann Perspect. 1998;30(2):67-88.

43. Ssewanyana D, Sebena R, Petkeviciene J, Lukács A, Miovsky M, Stock C. Condom use in the context of romantic relationships: A study among university students from 12 universities in four Central and Eastern European countries. Eur J Contracept Reprod Health Care. 2015;20(5):350-60.

Received September 1, 2017 Accepted in revised form October 15, 2018 